\title{
Matéria Orgânica em Solos Desenvolvidos de Rochas Máficas no Nordeste de Roraima
}

\author{
Valdinar Ferreira MELOํ, Carlos Ernesto Gonçalves Reynaud SCHAEFER² \\ RESUMO \\ Solos desenvolvidos de rochas máficas no nordeste de Roraima são cultivados continuamente por populações \\ indígenas em função da boa fertilidade natural. Este trabalho objetivou avaliar as alterações na matéria orgânica do \\ solo por meio do fracionamento das substâncias húmicas, aplicação de análises de CHNS, estudos termogravimétricos \\ e de Ressonância Paramagnética de Elétrons (EPR). Os maiores teores de C foram observados no Chernossolo \\ sob cultivo contínuo. A fração humina foi predominante em todos os solos, tendo seus teores reduzidos em \\ profundidade. No Nitossolo, houve menor relação ácido húmico/fúlvico. No Chernossolo cultivado, a posição no \\ relevo e a incorporação dos restos culturais parece ter contribuído para manter a estabilidade do solo. Nos demais Chernossolos, \\ a natureza química contribuiu para a ciclagem mais eficiente da matéria orgânica. No Chernossolo e nos Cambissolos \\ não cultivados, a matéria orgânica se apresentou menos estável. No Chernossolo sob cultivo, houve aumento da \\ polimerização do ácido húmico. Os solos com horizonte A chernozêmico, não cultivados, comportaram-se mais \\ uniformes quanto à qualidade dos ácidos húmicos.
}

PALAVRaS-CHAVE: Substâncias húmicas, Chernossolo, Amazônia, Agricultura itinerante.

\section{Organic Matter in Soils Developed from Mafic Rocks, in Northeastern Roraima}

\section{ABSTRACT}

Soils developed from mafic rocks in Northeastern Roraima are the preferred areas for indigenous shifting cultivation, in view of their high natural fertility. The study was focused on changes in the soil organic matter status, by means of humic substances fractionation, and application of CHNS analyses and termogravimetric studies and EPR. High C values were observed in Chernosol under continuous cultivation. The humin fraction was predominant in all soils, reducing with depth. The Nitosol showed smaller humic/fulvic acids ratio. The Chernosol under cultivation in a more conservative relief, with incorporation of crop residues, there was greater nutrient cycling. In the uncultivated Chernosol and Cambisol the soil organic matter was less stable. In the chernosol under cultivation, increasing polymerisation of humic acids was observed. The virgin soils with chernozemic A horizons were more homogeneous with respect to humic acid quality.

KEYWORDS: Humic substances, shiffting cultivation, Chernosol, Amazon.

1 Departamento de Solos e Engenharia Agrícola, UFRR, BR 174 s/n, 69310-250, Boa Vista, Roraima, Brazil. valdinar@yahoo.com.br

2 Departamento de Solos, Universidade Federal de Viçosa, MG 36571-000, Brazil. carlos.schaefer@ufv.br 


\section{INTRODUÇÃO}

A matéria orgânica do solo representa um sistema dinâmico, influenciado por vários fatores, desde o clima, o conteúdo de argila do solo, a mineralogia e os sistemas de manejo, que podem afetar os processos de transformação e evolução da matéria orgânica no solo (Haider, 1992; Oades, 1995).

A interferência antrópica sobre os ecossistemas produz mudanças na dinâmica da matéria orgânica do solo (Ney \& Greeland, 1964; Reicheli, 1981) tem causado maiores perdas do que ganhos nos conteúdos de carbono, com implicaçôes no solo ao longo do tempo (Doran, 1997). Estas açōes, realizadas em forma de práticas de uso e manejo dos solos, interferem no equilíbrio natural dos ecossistemas e altera os componentes orgânicos tanto em qualidade quanto em quantidade. Diante disso, constata-se uma dinâmica química e física diferente das condiçōes originais, com conseqüências variáveis, as quais dependem do manejo adotado (Stevenson, 1994). Além das variações em função do tempo e do tipo de uso, o conteúdo de $\mathrm{C}$ no solo varia também em função das condições ambientais e do tipo de solo (Koutika et al., 1997; Batjes \& Dijkshoorn, 1999).

Os solos com horizonte A Chernozêmico possuem grande expressão da interação das frações orgânicas do solo, influenciando nas características estruturais, na cor e nos teores de carbono orgânico, além da forte atuação dos microrganismos e da mesofauna do solo, em razão das condições de saturação por bases elevada (Anjos et al., 1999).

As substâncias húmicas são representadas por compostos orgânicos resultantes da atividade biológica, caracterizadas em função das suas estruturas e reatividade, separadas com base em suas características de solubilidade e classificadas como humina, ácidos húmicos e ácidos fúlvicos (Camargo et al., 1999). Os estudos quantitativos e qualitativos das substâncias húmicas consistem em técnicas de extração, fracionamento e purificação por meio de processos físico-químicos, usandose comumente soluções alcalinas e ácidas, dependendo da natureza de cada grupo funcional e caracterização espectroscópica (Stevenson, 1994).

Os ácidos fúlvicos, caracterizados por compostos de maior solubilidade dentre as substâncias húmicas, apresentam forte afinidade por elementos metálicos, formando compostos organo-metálicos, que, de acordo com as condiçôes ambientais, podem percolar pelo perfil do solo com a água de drenagem, ficando retidos nos horizontes inferiores ou fazendo parte dos cursos d'água (Lazerte \& Fundeis, 1994).

As substâncias orgânicas solúveis podem formar complexos com as fraçōes inorgânicas do solo, ser fortemente adsorvidas pelos argilominerias e óxidos de ferro e alumínio, além de poderem formar compostos presentes na solução do solo
(Davis, 1982), via mecanismos que possibilitam a formação de complexos catiônicos, aniônicos, ligação de hidrogênio, ligações covalentes e forças de Van der Walls (Sposito, 1989). Interações de moléculas orgânicas, através de grupos funcionais com os constituintes minerais do solo, influenciam desde a formação de horizonte até suas propriedades (Canellas et al., 1999).

Em solos com argila de atividade alta e caráter expansivo, a ciclagem da matéria orgânica nos horizontes superficiais é geralmente rápida (Coulombe et al., 1986) e depende das condiçóes ambientais e das práticas de manejo (Dell' Abate et al., 2002). Essa ciclagem tem uma relação direta com a disponibilidade de carbono para a atmosfera, podendo contribuir, de acordo com a qualidade da matéria orgânica, para aumentar ou diminuir o estoque de carbono no solo, com função de promover o seqüestro de carbono, uma vez que o solo é um dos principais componentes do ciclo de carbono terrestre (Swift, 2001).

Este trabalho teve como objetivo estudar as características da matéria orgânica em uma toposseqüência de solos desenvolvidos sob rochas máficas sob uso agrícola indígena no nordeste do Estado de Roraima.

\section{MATERIAL E MÉTODOS}

\section{PROCEDIMENTO DE AMOSTRAGEM}

As amostras de solos para a determinação do carbono orgânico e o fracionamento da matéria orgânica foram coletadas nos respectivos perfis dos solos correspondendo às profundidades dos respectivos horizontes, em uma topossequiência composta por cinco perfis de solos, desenvolvidos de rochas máficas (diabásio), que constitui um dos maiores corpos máficos do Norte Amazônico, o Sill "Pedra Preta". É uma área habitada pelos povos indígenas macuxís, denominada Maloca do Flechal, situada no nordeste do Estado de Roraima, município do Uriamutã, coordenadas geográficas $4^{\circ} 25^{\prime}$ e $4^{\circ} 45^{\prime} \mathrm{N}$; $60^{\circ} 15^{\prime}$ e $60^{\circ} 20^{\prime} \mathrm{W}$ (Figura 1). As amostras para caracterização dos ácidos húmicos por CHNS, Termogravimetria e EPR foram consideradas apenas às correspondentes aos horizontes superficiais de cada perfil de solo.

As classes de solos estudadas foram: P1 - NITOSSOLO VERMELHO Eutrófico (NVe), P2 - CHERNOSSOLO EBÂNICO Órtico (MEo), cultivado com lavoura anual e com a queima dos restos culturais, P3 e P5 - CAMBISSOLOS HÁPLICOS Tb Eutróficos (CXbe) e P4 - CHERNOSSOLO EBÂNICO Órtico vértico (MEov), cujas características químicas encontram-se na tabela 1 . Com exceção do solo perfil 2, todos os demais são utilizados como pasto nativo e sofrem ação constante de queima. 


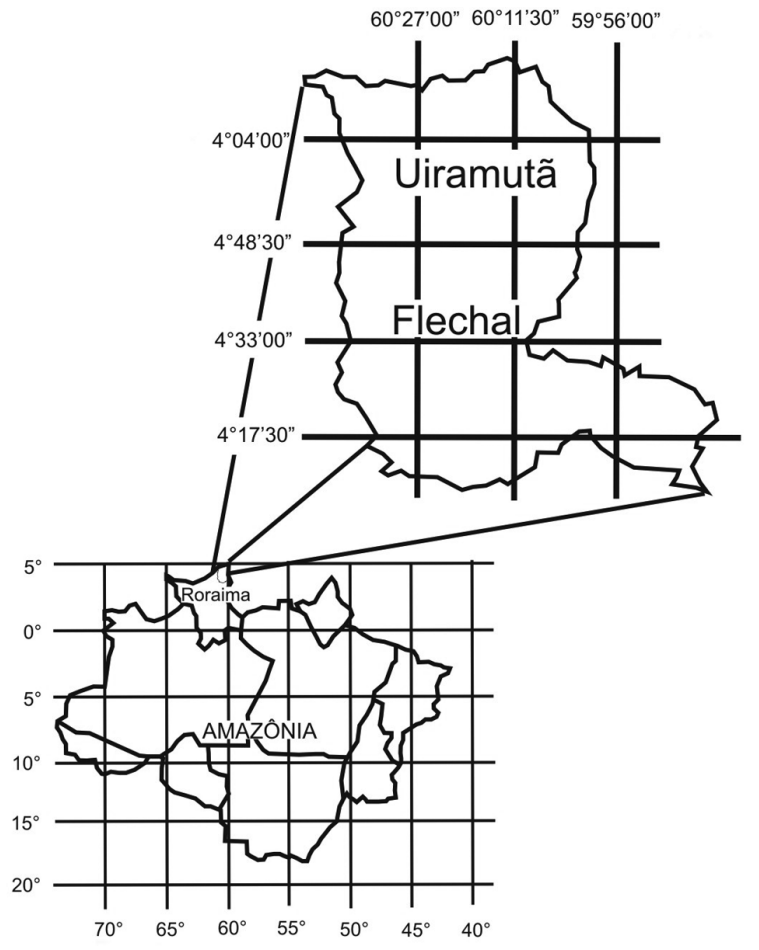

Figura 1 - Localização da área de estudo no Estado de Roraima (Região do Flechal pertencente ao município do Uiramutã)

\section{DETERMINAÇÃO QUANTITATIVA DO CARBONO ORGÂNICO TOTAL E FRACIONAMENTO DA MATÉRIA ORGÂNICA}

O carbono orgânico total foi determinado em triplicata, utilizando o método descrito por Yeomans \& Bremner (1988), e o fracionamento das substâncias húmicas foi realizado segundo a técnica do fracionamento diferencial estabelecida pela Sociedade Internacional de Substancias Húmicas (IHSS), descrito por Swift (1996). Os estoques de carbono e humina em kg.ha ${ }^{-1}$ foram estimados a partir dos valores de carbono em dag. $\mathrm{kg}^{-1}$, considerando os valores de densidade dos solos da região Amazônica (Batjes \& Dijkshoorn, 1999), dentro das respectivas profundidades de cada horizonte. As taxas de humificação foram calculadas de acordo com Ciavatta et al. (1990).

\section{EXTRAÇÃO E PURIFICAÇÃO DAS SUBSTÂNCIAS HÚMICAS PARA}

\section{FINS DE RESSONÂNCIA PARAMAGNÉTICA ELETRÔNICA (EPR)}

Os ácidos húmicos $(\mathrm{AH})$ das amostras superficiais $(\mathrm{n}=05)$ foram extraídos e purificados em amostras sólidas, por liofilização, segundo a técnica padrão adotada pela Sociedade Internacional de Substâncias Húmicas (IHSS) descrito por Swift (1996).

Os espectros de ressonância paramagnética eletrônica dos ácidos húmicos foram obtidos em amostras sólidas, utilizando um espectrômetro de EPR, Brucker EMX, operando em banda X $(9 \mathrm{GHz})$ e cavidade retangular, potência de 0,2 MW, amplitude de modulação de 1 Gauss, pico a pico.

Para quantificação dos radicais orgânicos livres dos ácidos húmicos foi utilizado o método do padrão secundário (Singer, 1959) com um cristal de rubi (Al2O3) contendo $0,5 \%$ de $\mathrm{Cr}+3$ por peso. Seu fator g é de 1,263 e, portanto, não interfere com o sinal do radical orgânico livre, cujo valor de g está em torno de 2,003 (Martin-Neto et al., 1998), obtendo-se a concentração de spins pela área dos radicais livres semiquinona através da fórmula aproximada I $\Delta \Delta \mathrm{H} 2$, em que I é a amplitude do sinal e $\Delta \mathrm{H}$ a largura da linha em Gauss, ambas medidas em espectro em primeira derivada.

Tabela 1 - Características químicas dos solos desenvolvidos de rochas máficas da região da Maloca do Flechal

\begin{tabular}{|c|c|c|c|c|c|c|c|c|c|c|c|c|c|}
\hline \multirow{2}{*}{ Solo } & \multirow{2}{*}{ Hor. } & $\mathrm{pH}$ & C & $\mathrm{Al}^{+3}$ & $\mathrm{H}+\mathrm{Al}$ & $\mathrm{Ca}^{+2}$ & $\mathrm{Mg}^{+2}$ & $\mathrm{~K}^{+}$ & SB & $\mathrm{T}$ & V & $\mathrm{m}$ & $P$ \\
\hline & & $\mathrm{H}_{2} \mathrm{O}$ & dag $\mathrm{kg}^{-1}$ & \multicolumn{7}{|c|}{ - } & \multicolumn{2}{|c|}{-------\%------ } & $\mathrm{mg} \mathrm{kg}^{-1}$ \\
\hline \multirow{3}{*}{ NVe } & Ap & 5,7 & 24,6 & 0,05 & 6,87 & 2,63 & 2.48 & 0,10 & 5,34 & 12,21 & 43 & 1 & 0,96 \\
\hline & $\mathrm{Bni}_{1}$ & 5,5 & 15,6 & 0,27 & 5,66 & 1,21 & 0,98 & 0.03 & 2,27 & 7,93 & 28 & 11 & 0,77 \\
\hline & $\mathrm{Bni}_{2}$ & 5,9 & 9,3 & 0,00 & 2,20 & 1,03 & 0.91 & 0,01 & 1,98 & 4,18 & 65 & 0 & 0,72 \\
\hline \multirow{3}{*}{ MEo } & $A p$ & 6,1 & 23,8 & 0,00 & 4,34 & 6,87 & 3,16 & 0,15 & 10,50 & 14,84 & 71 & 0 & 2,50 \\
\hline & $\mathrm{Bni}_{1}$ & 6,1 & 17,2 & 0,05 & 4,51 & 5,01 & 2.38 & 0.13 & 7,70 & 12,21 & 63 & 1 & 1,46 \\
\hline & $\mathrm{Bni}_{2}$ & 6,2 & 14,2 & 0,05 & 3,57 & 5,80 & 2,62 & 0,05 & 8,51 & 12,08 & 71 & 1 & 1,01 \\
\hline \multirow{3}{*}{ CXbe } & $A p$ & 6,8 & 15,3 & 0,05 & 2,75 & 8,69 & 2,79 & 0,05 & 11,64 & 14,39 & 81 & 0 & 1,33 \\
\hline & $\mathrm{Bi}_{1}$ & 7,2 & 10,8 & 0,00 & 2,09 & 9,05 & 0,30 & 0,04 & 9,50 & 11,59 & 82 & 0 & 1,25 \\
\hline & $\mathrm{Bi}_{2}$ & 7,3 & 9,5 & 0,00 & 1,54 & 9,21 & 0,00 & 0,05 & 9,38 & 10,92 & 86 & 0 & 1,44 \\
\hline \multirow{3}{*}{ MEov } & $A p$ & 7,0 & 20,6 & 0,00 & 2,53 & 9,31 & 0,04 & 0.05 & 9,35 & 11,88 & 79 & 0 & 1,16 \\
\hline & $\mathrm{Bi}_{1}$ & 7,3 & 6,9 & 0,00 & 1,37 & 10,50 & 0,08 & 0,07 & 10,79 & 12,16 & 86 & 0 & 1,46 \\
\hline & $\mathrm{Bi}_{2}$ & 7,4 & 3,7 & 0,00 & 1,43 & 12.70 & 0,06 & 0,05 & 12,92 & 14,35 & 90 & 0 & 1,39 \\
\hline \multirow{3}{*}{ CXbe } & $A p$ & 6,5 & 19,3 & 0,00 & 3,24 & 6,75 & 0,37 & 0,04 & 7,23 & 10,63 & 69 & 0 & 1,22 \\
\hline & $\mathrm{Bi}_{1}$ & 7,3 & 5,9 & 0,00 & 1,48 & 7,44 & 0,46 & 0,03 & 8,01 & 9,49 & 84 & 0 & 1,26 \\
\hline & $\mathrm{Bi}_{2}$ & 7,8 & 3,7 & 0,00 & 0,71 & 7,31 & 0,00 & 0,03 & 7,43 & 8,14 & 91 & 0 & 1,08 \\
\hline
\end{tabular}

NVE - Nitossolo Vermelho Eutrófico, MEo - Chernossolo Ebânico Órtico, CXBe - Cambissolo Háplico Tb Eutrófico, Chernossolo Ebânico Órtico vértico. 


\section{TERMOGRAVIMETRIA DOS ÁCIDOS HÚMICOS DE AMOSTRAS SUPERFICIAIS DOS SOLOS}

As análises termogravimétricas das amostras de ácidos húmicos de horizontes superficiais de solos $(\mathrm{n}=05)$ foram feitas em um analisador termogravimétrico TGA-50 SHIMADZU, usando amostras com peso em torno de 3,0 $\mathrm{mg}$, em ambiente estático ao ar. Iniciou-se o processo à temperatura de $30^{\circ} \mathrm{C}$ e a curva de aquecimento foi de $5^{\circ} \mathrm{C} \min ^{-1}$ até $105^{\circ} \mathrm{C}$, com um tempo de espera de $10 \mathrm{~min}$, seguido de aquecimento a $5^{\circ} \mathrm{C}$ $\mathrm{min}^{-1}$ até o valor máximo $750^{\circ} \mathrm{C}$, interrompendo o processo quando detectado o final da queima pela estabilização do peso do resíduo. O processo consumiu em média 2 horas e 30 minutos por amostra. As curvas de termodecomposição foram obtidas utilizando-se o programa TA-50 WSI, a uma razão de um ponto a cada 10 segundos, num total de 800 pontos por curva. A perda de peso até $105^{\circ} \mathrm{C}$, incluindo o tempo de espera, foi considerada como umidade da amostra. O resíduo ao final da queima foi considerado como o teor de cinzas (Huffman \& Stuber, 1985). Essa metodologia foi padronizada por (Benites, 2002).

\section{ANÁLISE ELEMENTAR (CHN) DOS ÁCIDOS HÚMICOS}

A composição elementar foi determinada em um analisador elementar Perkin Elmer PE-2400 CHNS. As análises foram feitas utilizando-se amostras de 1,1000 $\pm 0,1000 \mathrm{mg}$, pesadas em microbalança acoplada ao aparelho. $O$ padrão de referência usado foi a acetanilida ( $\mathrm{C}=71,09 \%, \mathrm{H}=6,71 \%, \mathrm{~N}=10,36 \%)$, e as leituras das amostras, alternadas por leituras de brancos, na razão de um branco para cada quatro amostras. Os valores de carbono, hidrogênio e nitrogênio foram corrigidos para base seca, utilizando as informaçôes obtidas pelos dados da análise termogravimétrica, através da seguinte equação:

$\%$ corrigido $=\%$ original $\times 100 /(100-\%$ umidade $\%$ cinzas).

\section{RESULTADOS E DISCUSSÃO}

\section{CARBONO ORGÂNICO TOTAL}

Os valores de carbono orgânico total (Tabela 2) evidenciam as diferenças entre os tipos de solos e as condições climáticas aos quais estão submetidos. O NVe apresentou maior estoque de carbono em superfície embora tenha horizonte A com dimensões inferiores aos demais solos. O MEo sob cultivo contínuo (P2), embora ofereça condiçōes de eutrofismo, que favorece uma mineralização mais ativa da matéria orgânica, mostrou que a incorporação de restos culturais e a queima contribuíram para manter os teores de carbono elevados em relação aos demais solos de natureza semelhante, sem a influência do cultivo. As características químicas destes parecem ser uma das condiçôes determinantes do conteúdo de carbono nos solos (Stevenson, 1994; Anjos et al., 1999), fato também observado por Benites (1998), estudando carbono no solo de diferentes pedoambientes de Minas Gerais e Vale Júnior (2000), quando comparou o estoque de carbono de solos desenvolvidos sobre rochas máficas e rochas ácidas nas regiōes do Taiano e Pacaraima, respectivamente, em Roraima.

Tabela 2 - Carbono orgânico total e em cada fração das substâncias húmicas, estoque de carbono e de humina e taxa de humificação em profundidade.

\begin{tabular}{|c|c|c|c|c|c|c|c|c|c|c|c|c|}
\hline \multirow{2}{*}{ Perfil } & \multirow{2}{*}{$\begin{array}{l}\text { Classes } \\
\text { de Solo }\end{array}$} & \multirow{2}{*}{ Hor. } & Prof. & AF & $\mathrm{AH}$ & HU & $\Sigma$ & \multicolumn{2}{|l|}{$\mathrm{HU}$} & \multirow{2}{*}{$\frac{C}{-k g ~ h a^{-1}-}$} & \multirow{2}{*}{$\begin{array}{c}\mathrm{TH} \\
-\%-\end{array}$} & \multirow[t]{2}{*}{$\mathrm{AH} / \mathrm{AF}$} \\
\hline & & & $\mathrm{Cm}$ & -----. & -.---- & $g^{-1}---\cdot-$ & ------ & -kg ha-1- & -dag kg-1- & & & \\
\hline \multirow{3}{*}{ P1 } & \multirow{3}{*}{ NVe } & $A p$ & $0-10$ & 3,75 & 5,04 & 15,88 & 24,67 & 19.508 & 2,46 & 30.258 & 36 & 1,34 \\
\hline & & $\mathrm{Bni}_{1}$ & $10-25$ & 2,10 & 2,91 & 8,08 & 13,10 & 14.917 & 1,56 & 28.782 & 32 & 1,39 \\
\hline & & $\mathrm{Bni}_{2}$ & $25-60$ & 0,78 & 0,25 & 3,77 & 4,79 & 16.208 & 0,93 & 40.037 & 11 & 0,32 \\
\hline \multirow{3}{*}{ P2 } & \multirow{3}{*}{ MEo } & $A p$ & $0-32$ & 1,85 & 5,49 & 16,67 & 24,01 & 67.213 & 2,38 & 95.962 & 31 & 2,97 \\
\hline & & $\mathrm{Bni}_{1}$ & $32-50$ & 1,23 & 3,69 & 7,10 & 12,03 & 16.114 & 1,72 & 39.010 & 29 & 3,00 \\
\hline & & $\mathrm{Bni}_{2}$ & $50-90+$ & 1,09 & 2,31 & 5,12 & 8,55 & 25.830 & 1,42 & 71.568 & 24 & 2,12 \\
\hline \multirow{3}{*}{ P3 } & \multirow{3}{*}{ CXbe } & $A p$ & $0-20$ & 1,26 & 1,11 & 10,99 & 13,36 & 27.707 & 1,53 & 38.556 & 15 & 0,88 \\
\hline & & $\mathrm{Bi}_{1}$ & $20-35$ & 0,59 & 0,29 & 5,58 & 6,46 & 10.546 & 1,08 & 34.020 & 8 & 0,49 \\
\hline & & $\mathrm{Bi}_{2}$ & $35-60+$ & 0,37 & 0,00 & 4,76 & 5,13 & 14.878 & 0,95 & 29.925 & 4 & 0,00 \\
\hline \multirow{4}{*}{ P4 } & \multirow{4}{*}{ MEov } & $A p$ & $0-20$ & 1,17 & 1,41 & 9,83 & 12,41 & 24.784 & 2,06 & 51.912 & 12 & 1,21 \\
\hline & & $\mathrm{Bi}_{1}$ & $20-38$ & 0,08 & 0,15 & 2,69 & 2,92 & 6.090 & 0,69 & 15.649 & 03 & 1,88 \\
\hline & & $\mathrm{Bi}_{2}$ & $38-58$ & 0,04 & 0,09 & 1,98 & 2,11 & 4.977 & 0,37 & 9.324 & 03 & 2,25 \\
\hline & & $\mathrm{Bi}_{3}$ & $58-90+$ & 0,05 & 0,72 & 2,19 & 2,96 & 8.830 & 0,40 & 16.128 & 19 & 14,40 \\
\hline \multirow{4}{*}{ P5 } & \multirow{4}{*}{ CXbe } & $A p$ & $0-30$ & 1,36 & 0,60 & 11,61 & 13,57 & 43.905 & 1,93 & 72.954 & 10 & 0,44 \\
\hline & & $\mathrm{Bi}_{1}$ & $30-83$ & 0,11 & 0,33 & 2,21 & 2,65 & 14.758 & 0,59 & 39.400 & 07 & 3,00 \\
\hline & & $\mathrm{Bi}_{2}$ & $83-111$ & 0,05 & 0,00 & 1,80 & 1,85 & 6.368 & 0,37 & 13.054 & 1,4 & 0,00 \\
\hline & & $\mathrm{Bi}_{3}$ & $111-163$ & 0,06 & 0,00 & 1,16 & 1,22 & 10.156 & 0,42 & 27.518 & 1,4 & 0,00 \\
\hline
\end{tabular}

$\mathrm{AF}$ - ácido fúlvico, $\mathrm{AH}$ - ácido húmico, $\mathrm{HU}$ - humina; $\Sigma$ - somatório das frações $\mathrm{AF}, \mathrm{AH}$ e HU; $\mathrm{TH}$ - Taxa de humificação $=100 \times \mathrm{C}(\mathrm{AF}+\mathrm{AH}) / \mathrm{C}$ orgânico, NVE - Nitossolo Vermelho Eutrófico, MEo - Chernossolo Ebânico Órtico, CXBe - Cambissolo Háplico Tb Eutrófico, Chernossolo Ebânico Órtico vértico. 


\section{FRACIONAMENTO DA MATÉRIA ORGÂNICA}

A fração humina foi a predominante em todos os solos, com variaçōes entre 54 e $94 \%$ das substâncias húmicas (Tabela 1). Em todos os solos houve decréscimo da fração humina em profundidade, que apresentou correlação positiva com os teores de carbono $\left(r=0,95^{* * *}\right)$.

No MEo (P2), a prática de cultivo e o relevo devem ter contribuído para manter os níveis de matéria orgânica em condiçôes superiores aos demais solos, principalmente em profundidade. Como o solo ocupa uma posição mais baixa na paisagem e há um retorno de restos culturais associado à queima, os valores de carbono mantiveram-se elevados. Tal fato contribuiu para a sustentabilidade do sistema de produção agrícola, conforme reportado pelo líder da Maloca, o Índio Macuxi Arnaldo: "Esta terra preta (Eri-ktun) tem mantido o sustento de sua família por muitas décadas, com cultivos anuais e de fruteiras". Assim, postula-se que a própria formação de horizontes A chernozêmicos na região Amazônica, sobre solos eutróficos, seja resultante do cultivo com uso prolongado do fogo, a exemplo da formação de terras pretas de índio sobre restos cultuais ricos.

As frações húmicas do NVe denotaram o processo de argiluviação associado à mobilidade de formas mais solúveis, observado por meio da relação ácidos fúlvicos/ácidos húmicos $(\mathrm{AF} / \mathrm{AH})$, que diminuiu em profundidade. A fração humina predominou em todas as profundidades dos perfis analisados, com teores decrescentes em profundidades, correlacionandose diretamente com os teores de carbono orgânico total. Em relação às frações ácidos húmicos, a menor mobilidade foi atribuída à sua baixa solubilidade em condições ácidas. Observaçōes semelhantes foram feitas por Vale Júnior (2000) em Argissolo Vermelho desenvolvido de diabásio na Colônia Agrícola do Taiano, em ambiente de temperatura mais elevada.

Observou-se teores muito baixos das frações ácidos fúlvicos e ácidos húmicos nos solos CXbe (P3 e P5) e MEov (P4), atingindo valores negligenciáveis em alguns horizontes mais profundos. Essa redução pode ser atribuída às condiçôes químicas dos solos que favorecem a atividade microbiana, acelerando o processo de mineralização da matéria orgânica nas camadas superficiais. Além disso, as condiçōes de $\mathrm{pH}$ elevado, favorecendo a solubilidade dessas fraçōes, contribuem para uma baixa estabilidade desses constituintes orgânicos (ácidos fúlvicos e ácidos húmicos), somando às condiçōes de relevo acidentado, que facilita a remoção de formas solúveis de compostos orgânicos. A ação do fogo sobre a pastagem, nos períodos de seca, contribui para a redução dos ácidos fúlvicos e húmicos, aumentando o "turnover" da matéria orgânica e o conteúdo de humina residual.

No NVe, solo mais intemperizado,os valores de humina representaram um estoque expressivo de carbono de baixa ciclagem, cujos valores alcançam até $50.633 \mathrm{~kg}$. ha ${ }^{-1}$ na camada de $0-60 \mathrm{~cm}$ (Tabela 2). Porém no MEo (P2), sob constante uso agrícola, com a queima parcial dos restos culturais, o estoque de humina, dentro dos $50 \mathrm{~cm}$, é cerca de $83000 \mathrm{~kg}$. $\mathrm{ha}^{-1}$, superando os demais solos. Esses valores superaram até mesmo as estimativas de carbono feitas por Moraes et al. (1995), até $1 \mathrm{~m}$ de profundidade do solo, para os solos da Amazônia.

A taxa de humificação é um parâmetro que pode prover informaçôes quantitativas sobre as substâncias húmicas em relação à matéria orgânica total do solo (Ciavatta et al., 1990), evidenciando o grau de estabilidade dessa matéria orgânica. No presente estudo, as maiores taxas de humificação foram obtidas para os solos NVe e MEo (P2).

\section{EPR DE ÁCIDOS HÚMICOS EXTRAÍDOS DE HORIZONTES SUPERFICIAIS}

A quantificação dos radicais livres do tipo semiquinona, através da concentração de spins. $\mathrm{g}^{-1}$ de C (Tabela 3), resulta em informaçōes importantes na avaliação qualitativa da fração ácidos húmicos da matéria orgânica dos solos em estudo. Maiores concentrações de radicais livres no Chernossolo (cultivado por mais de 20 anos, perfil 2) e no Nitossolo corroboram a taxa de humificação e vêm fundamentar o efeito das práticas de cultivo e da fertilidade do solo na qualidade da matéria orgânica, contribuindo para entender as complexas interações físico-químicas que ocorrem com a matéria orgânica de acordo com o ambiente em que se encontra. $\mathrm{O}$ aumento da concentração de radicais livres semiquinona no Chernossolo sob cultivo resulta do tipo de manejo com uso do fogo. A exploração contínua do solo por longo tempo, com a queima dos resíduos vegetais, aumenta a aromaticidade dos ácidos húmicos, em conseqüência da concentração dos radicais livres semiquinonas, resultantes da remoção oxidativa do hidrogênio dos $\mathrm{OH}$ se grupos fenóis (Riffaldi \& Schnitzer, 1972). A carbonização dos materiais vegetais resulta no aumento considerável da aromaticidade com redução dos grupos carboxílicos e estruturas alifáticas (Seiler \& Crutzen, 1980; Almendros, et al. 1992). Os anéis aromáticos são estruturas mais resistentes à mineralização $\mathrm{e}$ funcionam como diagnóstico da existência de "black carbon" em áreas com alta incidência de fogo, com elevadas taxas de oxidação (Haumaier \& Zech, 1995).

Esses fenômenos podem ser melhor visualizados nas curvas dos espectros de EPR (Figura 2), em que a amostra 2 destaca-se em relação às demais, em termos de largura da base.

Essas informações permitiram fazer inferências sobre a qualidade da matéria orgânica em diferentes condiçōes de ambientes, suas implicaçōes na gênese dos solos, além das alteraçôes provocadas em função da queima e das condições de fertilidade. Os solos de melhor fertilidade (P3, P4 e P5), 
Tabela 3 - Radicais livres do tipo semiquinona determinados por ressonância paramagnética eletrônica de ácidos húmicos de amostras de horizontes superficiais de diferentes solos.

\begin{tabular}{lccrrr}
\hline Perfil & Solo & Hor. & $\begin{array}{r}\text { Spin/g } \\
\times 10^{16}\end{array}$ & $\begin{array}{r}\text { Massa de C } \\
(\mathrm{mg})\end{array}$ & $\begin{array}{r}\text { Spin/g de C } \\
\times 10^{16}\end{array}$ \\
\hline P1 & NVe & Ap & 1,130 & 7,802 & 3,78 \\
P2 & ME0 & Ap & 6,400 & 15,056 & 12,22 \\
P3 & CXbe & Ap & 0,287 & 7,272 & 0,96 \\
P4 & MEov & Ap & 0,117 & 4,114 & 0,35 \\
P5 & CXbe & Ap & 0,489 & 9,274 & 1,10 \\
\hline
\end{tabular}

P1, P2, P3, P4 e P5 - Perfis dos solos estudados, Hor. - Horizonte, Ap - horizonte superficial. NVe - Nitossolo Vermelho Eutrófico, MEo - Chernossolo Ebânico Órtico, CXBe - Cambissolo Háplico Tb Eutrófico, Chernossolo Ebânico Órtico vértico.

com menores concentrações de spins $\mathrm{g}^{-1} \mathrm{e}$ taxa de humificação têm como conseqüência a menor estabilidade da $\mathrm{MO}$ e rápida ciclagem.

\section{COMPOSIÇÃO ELEMENTAR DE ÁCIDOS HÚMICOS EXTRAÍDOS DE HORIZONTES SUPERFICIAIS}

A análise dos conteúdos relativos de carbono, hidrogênio, nitrogênio e oxigênio revelam a natureza química da matéria orgânica (Tabela 4). As amostras de ácidos húmicos apresentaram valores de carbono inferiores aos valores médios estabelecidos por Steelink (1985), sendo que apenas o solo MEo situou-se dentro dessa média. Esses resultados expressam certa tendência de maior ciclagem de $\mathrm{C}$ em condiçōes de eutrofismo, retardando o processo de humificação. No caso do MEo, sob cultivo, as práticas de cultivo por longo tempo com uso do fogo podem ter condicionado à formação de ácidos húmicos de maior polimerização, favorecendo o aumento dos percentuais de carbono mais estável, visto que a queima da matéria orgânica promove o aumento da polimerização dos ácidos húmicos (Santos et al., 2001).

\section{TERMODECOMPOSIÇÃO DOS ÁCIDOS HÚMICOS}

A resistência termal dos ácidos húmicos de horizontes superficiais (Tabela 5) mostra eventos diferenciados de termodecomposição entre os materiais, com várias fases bem

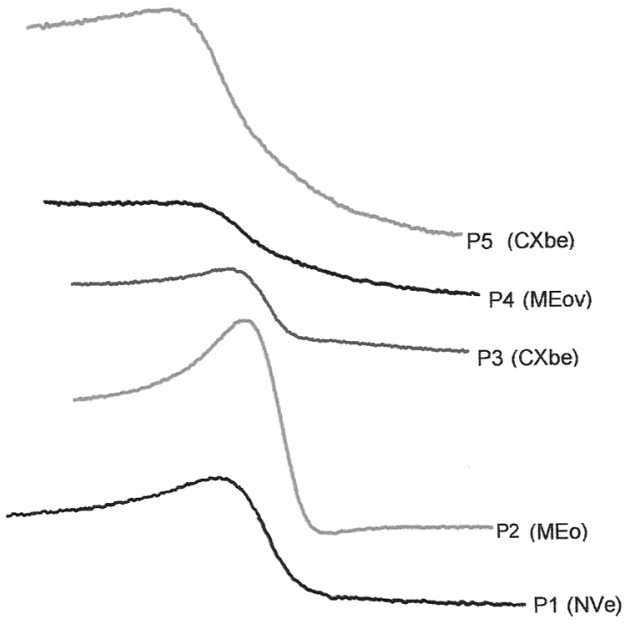

$\begin{array}{llcc}3340 & 3350 & 3360 & 3370 \\ \text { Campo maanético (Gauss) }\end{array}$

Figura 2 - Curvas dos espectros de ressonância paramagnética de elétrons (EPR) de ácidos húmicos de amostras de horizontes superficiais dos perfis P1, P2, P3, P4 e P5, dos solos estudados

evidenciadas na Figura 3. Segundo Ibarra et al. (1994) e Benites (2002), as perdas ocorridas em temperaturas entre 105 e $350^{\circ} \mathrm{C}$ correspondem à decomposição de grupos funcionais de cadeias alifáticas, enquanto em temperaturas superiores ocorre a termodegradação de grupos funcionais com presença de núcleos aromáticos. As diversas fases observadas nas curvas de termodecomposição indicam variaçôes expressivas na composição dos ácidos húmicos, tanto nas estruturas de cadeias alifáticas como nas de cadeias com núcleos aromáticos. As amostras com mais homogeneidade na composição, menores oscilaçóes nas curvas, foram as dos perfis 3 e 4 , que representam os Chernossolos com maior eutrofismo e com menor instabilidade da matéria orgânica, em conseqüência com baixo grau de polimerização das substâncias húmicas.

Tabela 4 - Composição elementar de ácidos húmicos das amostras superficiais dos solos da região do Flechal, município do Uiramutã - RR.

\begin{tabular}{|c|c|c|c|c|c|c|c|c|c|c|}
\hline \multirow{3}{*}{ Classes de Solo } & \multirow{3}{*}{ Hor. } & \multirow{2}{*}{ Peso } & C & $\mathrm{H}$ & $\mathrm{N}$ & 0 & \multirow{3}{*}{$\mathrm{C}: \mathrm{N}$} & \multirow{3}{*}{$\mathrm{H}: \mathrm{C}$} & \multirow{2}{*}{ Umidade } & \multirow{2}{*}{ Cinzas } \\
\hline & & & & \multicolumn{3}{|c|}{ Sem cinzas } & & & & \\
\hline & & $\mathrm{mg}$ & & 9 & & & & & & \\
\hline MEo & $A p$ & 1,148 & 52,28 & 3,90 & 3,82 & 40,00 & 15,9 & 0,9 & 7,1 & 0,3 \\
\hline CXbe & $A p$ & 1,115 & 29,99 & 3,49 & 2,98 & 63,54 & 11,7 & 1,4 & 4,4 & 9,3 \\
\hline MEov & $A p$ & 1,141 & 33,32 & 5,30 & 4,37 & 57,01 & 8,9 & 1,9 & 2,5 & 47 \\
\hline CXbe & $A p$ & 1,153 & 44,33 & 4,35 & 3,49 & 47,83 & 14,8 & 1,2 & 5,6 & 28 \\
\hline
\end{tabular}

P1, P2, P3, P4 e P5 - Perfis dos solos estudados. NVe - Nitossolo Vermelho Eutrófico, MEo - Chernossolo Ebânico Órtico, CXBe - Cambissolo Háplico Tb Eutrófico, Chernossolo Ebânico Órtico vértico.. 
Tabela 5 - Análise termogravimétrica de ácidos húmicos extraídos de amostras de horizontes superficiais dos solos estudados.

\begin{tabular}{|c|c|c|c|c|c|c|}
\hline \multirow{2}{*}{ Perfil } & \multirow{2}{*}{$\begin{array}{l}\text { Classes de } \\
\text { Solos }\end{array}$} & Umidade & Cinzas & \multicolumn{2}{|c|}{ PPI\% } & \multirow{2}{*}{$\begin{array}{l}\text { Qmáx } \\
{ }^{\circ} \mathrm{C}\end{array}$} \\
\hline & & --------\% & ----- & $105-350^{\circ} \mathrm{C}$ & $350-650^{\circ} \mathrm{C}$ & \\
\hline P1 & NVe & 4,4 & 0,9 & 24,46 & 75,54 & 635 \\
\hline P2 & MEo & 7,1 & 0,3 & 33,95 & 66,05 & 650 \\
\hline P3 & CXbe & 4,4 & 9,3 & 12,13 & 87,87 & 630 \\
\hline P4 & MEov & 2,5 & 47 & 50,67 & 49,33 & 600 \\
\hline P5 & CXbe & 5,6 & 28 & 41,63 & 58,37 & 594 \\
\hline
\end{tabular}

P1, P2, P3, P4 e P5 - Perfis dos solos estudados. PPI-perdas de peso por ignição. Omáx - energia máxima utilizada na combustão dos ácidos húmicos. NVe - Nitossolo Vermelho Eutrófico, MEo - Chernossoolo Ebânico Órtico, CXBe - Cambissolo Háplico Tb Eutrófico, Chernossolo Ebânico Órtico vértico.

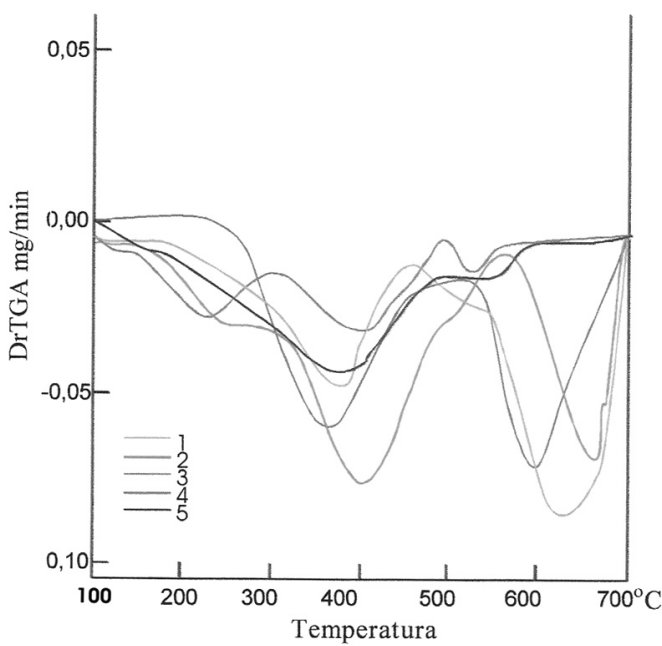

Figura 3 - Gráfico das primeiras derivadas das curvas de termodecomposição (DrTGA) de ácidos húmicos de horizontes superficiais. Os números 1, 2, 3, 4 e 5 são respectivamente os perfis P1, P2, P3, P4 e P5 dos solos.

\section{CONCLUSÕES}

O cultivo contínuo do solo Chernossolo com incorporação dos restos culturais proporcionou teores mais elevados de carbono.

A fração humina predominou em todos os solos, com decréscimo em profundidade.

No Nitossolo foi evidenciado maior mobilidade das frações húmicas, expressado pela relação ácidos fúlvicos/ ácidos húmicos.

No perfil 2 (Chernossolo), a posição no relevo plano e a incorporação dos restos culturais contribuíu para manter a estabilidade da matéria orgânica do solo.

Os dados de EPR revelam que no Chernossolo sob cultivo houve aumento da polimerização dos ácidos húmicos.

Os perfis de Chernossolos não cultivados apresentaram menor variação em termo de qualidade dos ácidos húmicos.

\section{BIBLIOGRÁFIA CITADA}

Almendros, G.; González-Vila, F.J.; Martin F.; Fründ R.; Lüdemann, H.D. 1992. Solid state NMR studies of fire-induced changes in the structure of humic substances. Science Total Environmental, 117:63-74.

Anjos, L.H.C.; Pereira, G.M.; Ramos, D.P. 1999. Matéria orgânica e pedogênese. In: Santos, G.A.; Camargo, F.A.O. Fundamentos da matéria organica do solo: ecossitemas tropicais e subtropicais. Subtropicais. Genesis, Porto Alegre. p.91-115.

Batjes, N.H.; Dijkshoorn, J.A. 1999. Carbon and nitrogen stocks in the soils of the Amazon Region. Geoderma, 89:273-286.

Benites, V.M. 1998. Caracterização química de espectroscópia da matéria orgânica e suas relaçôes com a gênese de solos da Serra do Brigadeiro, Zona da Mata Mineira. Tese de mestrado. Universidade Federal de Viçosa, Viçosa, 123p.

Benites, V.M. 2002. Caracterização de solos e das substânicas húmicas em Complexo Rupestre de Altitude. Tese de Doutorado. Universidade Federal de Viçosa, Viçosa. 130p.

Camargo, F.A.O.; Santos, G.A.; Guerra, J.G.M. 1999. Macromoléculas e substâncias húmicas. In: Santos, G. A.; Camargo, F.A. O. Fundamentos da matéria orgânica do solo: ecossitemas tropicais e subtropicais Genesis, Porto Alegre. p.27-39.

Canellas, L.P.; Santos, G. A.; Sobrinho, N.M.B.B. 1999. Reações da matéria orgânica do solo. In: Santos, G. A.; Camargo, F.A. O. Fundamentos da matéria orgânica do solo: ecossistemas tropicais e subtropicais. Genesis, Porto Alegre. p.69-89.

Ciavatta, C.; Govi, M.; Vittori Antisari, L.; Sequi, P. 1990. Characterization of humified compounds by extraction and fractionation on solid polyvinylpyrrolidone. Journal of Chromatography, 509:141-146.

Coulombe, C.E.; Dixon, J.B.; Wilding, L.P. 1986. Mineralogy and chemistry of Vertisols. In: Ahmad, N.; Mermut, A. (Eds), Vertisols and technologies for their management. Developments in Soil Science, p115-200.

Davis, J.A. 1982. Adsorption of natural dissolved organic matter at the oxide/water interface. Geochemica Cosmochimica Acta, 46:2381-2393.

Dell'Abate, M.T.; Benedetti, A.; Trinchera, A.; Dazzi, C. 2002. Humic substances along the profile of two Typic Haploxerert. Geoderma, 107:281-296.

Doran, J.W. 1997. Soil quality and sustainability. In: 26 Congresso Brasileiro de Ciência do Solo. Rio de Janeiro. CDROM... Rio de Janeiro: SBCS.

Haider, K. 1992. Problems related to the humification processes in soil of temperate climates. In: Stotzky, G.; Bollag, J.M. (Eds). Soil Biochemistry, 7:55-94.

Haumaier, L.; Zech, W. 1995. Black carbon - possible source of highly aromatic components of soil humic acids. Organic Geochemistry, 23:191-196.

Huffman, E.W.D.; Stuber, H.A. 1985. Analytical methodology for elemental analysis of humic substances. In: Aiken, G.R.; McKnight, R.L; MacCarthy. (Eds), Humic substances in soil, sediment and water: geochemistry, isolation and characterization. John Wiley, New York. p.433-455. 
Ibarra, J.V.; Moliner, R.; Bonet, A. J. 1994. Thermal alteration of coal humic acids simulating early coalification. In: Senesi, N.; Miano, T.M. (Eds). Humic substances in the global environment and implications on human health. Elsevier, p.1325-1330.

Koutika, L.S.; Bartoli, F.; Andreux, F.; Cerri, C.C.; Burtin, G.; Choné, Th.; Philippy, R. 1997. Organic matter dynamics and aggregation in soils under rain forest and pastures of increasing age in the eastern Amazon Basin. Geoderma, 76:87-112.

Lazerte, B.; Fundeis, J. 1994. Acidic leaching of a Podzol Bf horizon from the precabriam shield. Communication Journal Soil Science, 74:321-333.

Martin-Neto, L.; Rossel, R.; Sposito, G. 1998. Correction of spectroscopic indicators of humification with mean annual rainfall along a temperature grassland climossequence. Geoderma, 81:305-311.

Moraes, J.L.; Cerri, C.C.; Melillo, J.M.; Kicklighter, D.; Neill, C.; Skole, D.L.; Steuder, A. 1995. Soil carbon stocks of the Brazilian Amazon Basin. Soil Science Society American Journal, 59:244-247.

Ney, P.H.; Greeland, D.J. 1964. Changes in the soil after clearing tropical forest. Plant \& Soil, 21:101-107.

Oades, J.M. 1995. An overview of processes affecting the cycling of organic carbon in soils. In: Zepp. R.G.; Sonntag, C. (Eds). Role of Non Living Organic Matter in the Earth's Carbon Cycle. John Wiley, New York. p.55-94.

Reicheli, M. 1981. Dynamic properties offorestry ecosystem. Cambridge, International Biological Program. Cambridge University Press. $683 \mathrm{p}$.

Riffaldi, R.; Schnitzer, M. 1972. Electron spin resonance spectrometry of humic substances. Soil Science Society of America Proceedings, 36:301-305.

Santos, R.S.O.; Kato, M.S.A.; Kato, O.; Novotny, E.H.; GonzálezPérez, M.; Martin-Neto, L.; 2001. Caracterização por EPR de ácidos húmicos de um Latossolo Amarelo com queima ou sem queima da vegetação na Amazônia Oriental. In: $4^{\circ}$ Encontro Brasileiro de Substancias Húmicas. Universidade Federal de Viçosa, Viçosa, Anais, Resumos expandidos, p.246-248.
Seiler, W.; Crutzen, P.J. 1980. Estimates of gross and net fluxes carbon between the biosphere and the atmosphere from biomass burning. Climatic Change, 2:207-247.

Singer, L.S. 1959. Synthetic ruby as a secondary standard for the measurement of intensities in Electron Paramagnetic Resonance. Journal Applied Physics, 30:1463-1464.

Sposito, G. 1989. Soil organic matter. In: The Chemestry of Soils. Oxford University Press, New York. p.42-61.

Steelink, C. 1985. Elemental characteristics of Humic Substances. In: Aiken, G.R.; Mcknight, D.M.; Wershaw, R.L.; MacCarthy, P. (Eds), Huminc Substances in soil, sediment and water. John Wiley, New York. p.457-476.

Stevenson, F.J. 1994. Humus Chemistry. Genesis, Composition, Reactions. John Wiley, New York. 443p.

Swift, R.S. 1996. Organic matter characterization. In: Methods of Soil Analysis. Part 3. Chemical Methods. Sparks, D.L. et al., (eds). Soil Science Society of America, p.1011-1069.

Swift, R.S. 2001. Sequestration of carbon by soil. Soil Science, 166:859-871.

Vale Júnior, J.F. 2000. Pedogênese e alterações dos solos sob manejo itinerante, em áreas de rochas vulcânicas ácidas e básicas, no nordeste do Roraima. Tese de Doutorado, Universidade Federal de Viçosa, Viçosa. 185p.

Yeomans, J.C.; Bremner, J.M. 1988. A rapid and precise method for routine determination of organic carbon in soil. Communication Soil Science Plant Analysis, 19:1467-1476.

Recebido em 16/01/2008

Aceito em 09/11/2008 